International Journal of Agriculture and Environmental Research

ISSN: 2455-6939

Volume: 07, Issue: 03 "May-June 2021"

\title{
LONG TERM STUDIES TO EVALUATE SOIL FERTILITY FOR CITRUS IN SARPANG, BHUTAN: CURRENT PRACTICES AND NUTRIENT STATUS
}

\author{
*S. Chhetri, T. Uden, T. Pem, M. Gurung and K. L. Jamtsho \\ National Soil Services Centre, Post Box No. 907, Semtokha, Thimphu, Bhutan. \\ *Corresponding Author
}

DOI: https://doi.org/10.51193/IJAER.2021.7307

\begin{abstract}
Citrus represents Bhutan's largest fresh fruit export. It is one of the main sources of income for rural households. However, citrus production is declining over the years mostly due to low soil fertility. This paper is the results of the long term studies conducted in 2013 and 2018 to determine the status and development in soil fertility management. Over 200 soil samples were collected from six villages. The soil samples were analyzed and interpreted for $\mathrm{pH}$, organic matter percent $(\mathrm{OM} \%)$, primary nutrients, carbon to nitrogen ratio $(\mathrm{C}: \mathrm{N})$, cation exchange capacity (CEC), and base saturation percent (BS\%). The results revealed that soil $\mathrm{pH}$ values were within a very acidic range and lower than the optimum $\mathrm{pH}$ level of 5.5-6.5. The average OM content was within moderate range and no change was observed over the years in soil fertility rating. The level of phosphorous $(\mathrm{P})$ decreased over the years but no major difference was observed in the fertility rating of total nitrogen percent $(\mathrm{N} \%)$. Deficiency in potassium $(\mathrm{K})$ was observed, and most of the soils recorded low $\mathrm{K}$ levels in both years. The $\mathrm{C}: \mathrm{N}$ ratio was within moderate to good range, CEC improved over the years but $\mathrm{BS} \%$ remained to be on the lower side indication acidic soils.
\end{abstract}

Keywords: Citrus, Soil fertility, Soil nutrient

\section{INTRODUCTION}

In Bhutan, citrus refers exclusively to mandarin (Citrus reticulate Blanco), which constitutes more than $95 \%$ of total citrus production in the country (Joshi \& Gurung, 2009). Citrus represents Bhutan's largest fresh fruit export, significantly contributing to Bhutan's economy by generating annual export revenue of $\mathrm{Nu} .464$ Million. It is one of the main sources of income for more than $38.5 \%$ of rural households and benefits more than $60 \%$ of the population The average 
International Journal of Agriculture and Environmental Research

ISSN: $2455-6939$

Volume: 07, Issue: 03 "May-June 2021"

annual citrus production over the last 10 years has been about 41,077 MT, and the area as of 2017 is 13,992 acres (DoA, 2019). However, despite the potential to increase citrus production and the existing export market in Bangladesh and India, the citrus industry in Bhutan is experiencing a rapid decline. The national yield $\left(3.9\right.$ tons acre $\left.{ }^{-1}\right)$ is far below the average yield of Thailand and Taiwan (6 tons acre ${ }^{-1}$ ) (Dorji et al., 2016). The decline in citrus yield is mainly due to poor technology adoption and traditional system of management (Drukpa, 2012). In fact, most of the citrus orchards are established on poor, marginal, and mountainous terrain. Most of citrus growers adopt traditional soil fertility and plant nutrition systems with inadequate nutrient management knowledge resulting in the low application of fertilizers to match citrus growth and high yield.

Therefore this paper provides an overview of the farmers' soil fertility management system in citrus and trend in soil nutrient status. The paper concludes by identifying key interventions for improving soil fertility for citrus.

\section{MATERIALS AND METHOD}

The National Soil Services Centre (NSSC), Department of Agriculture, Ministry of Agriculture and Forests (MoAF), Bhutan, conducted long term studies on citrus. The study was conducted over a period of 6 years from 2013 to 2018. Soil samples were collected along with the information on farmers' soil fertility management practices using a structured questionnaire format. The soil samples were analysed in Soil and Plant Analysis Laboratory (SPAL) of the NSSC.

\subsection{Description of the study area}

A field survey/study was conducted in one of the major citrus growing areas in the southern part of Bhutan in Sarpang, A total of six villages were selected based on the list prepared by the respective agriculture officers of these villages. A total of 134 households were sampled. The soil samples were collected from an altitude range of $149-1206 \mathrm{~m}$. asl. The number of citrus trees varied from 60 to 2000 with an average area of 2.10 acres from the sampled areas. About $68 \%$ orchards were situated with moderate slopes (slope gradient $<25 \%$ ) and $38 \%$ were situated on steep slopes (slope gradient $>50 \%$ ) with mostly facing north, northeast, and northwest aspects.

\subsection{Soil sampling}

Soil samples from citrus orchards were taken from 8-10 randomly selected points from the orchard. The orchards were divided into at least 8-10 parts in random for an area of not more than 1 ha. Following the tree canopy, soil samples from minimum of 8-10 parts were collected at 
a depth $15 \mathrm{~cm}$ representing top soil and $40 \mathrm{~cm}$ representing sub-soils from the same pit using soil augur. Samples were mixed separately to form two composite samples, top and sub soil respectively. The composite sample of $1 \mathrm{~kg}$ was sealed in a plastic bag with a proper level indicating name, location, and lot size. In total 270 and 202 nos of soil samples (top and sub) were collected and analyzed from 2013 to 2018.

\subsection{Soil Fertility ratting chart}

Table 1: The soil analysis result: very low, low, medium, high and very high

\begin{tabular}{|c|c|c|c|c|c|}
\hline $\begin{array}{l}\text { Soil } \\
\text { variables }\end{array}$ & $\begin{array}{l}\text { Very } \\
\text { low }\end{array}$ & low & $\begin{array}{l}\text { Medium } \\
\text { (Critical } \\
\text { level) }\end{array}$ & High & $\begin{array}{l}\text { Very } \\
\text { high }\end{array}$ \\
\hline $\mathrm{pH}(\mathrm{H} 20)$ & $<4.5$ & $\begin{array}{l}4.6 .5 . \\
5\end{array}$ & $5.6-6.5$ & $\begin{array}{l}6.6- \\
7.5\end{array}$ & $>7.5$ \\
\hline $\mathrm{N} \%$ & $<0.1$ & $\begin{array}{l}0.1- \\
0.19\end{array}$ & $0.2-0.49$ & $\begin{array}{l}0.5- \\
0.99\end{array}$ & $>1.0$ \\
\hline OM\% & 1.0 & 1.90 & 5.20 & 8.43 & $\begin{array}{l}>8.4 \\
3\end{array}$ \\
\hline $\mathrm{C}: \mathrm{N}$ ratio & 9.9 & $\begin{array}{l}10- \\
14.9\end{array}$ & $15-19.9$ & $\begin{array}{l}20- \\
49.9\end{array}$ & $>50$ \\
\hline $\begin{array}{l}\text { Av. P } \\
(\mathrm{mg} / \mathrm{kg})\end{array}$ & $<5$ & $5-14.9$ & $15-29.9$ & $>30$ & \\
\hline $\begin{array}{l}\text { Av.K } \\
(\mathrm{mg} / \mathrm{kg})\end{array}$ & $<40$ & $40-99$ & 100-199 & $\begin{array}{l}200- \\
299\end{array}$ & $>300$ \\
\hline $\begin{array}{l}\text { CEC } \\
(\mathrm{me} / 100 \mathrm{~g})\end{array}$ & $<5$ & $5-14.9$ & $15-24.9$ & $\begin{array}{l}25- \\
39.9\end{array}$ & $>40$ \\
\hline $\mathrm{BS} \%$ & $<35$ & $\begin{array}{l}35- \\
49.9\end{array}$ & $50-64.9$ & $\begin{array}{l}65- \\
79.9\end{array}$ & $>80$ \\
\hline
\end{tabular}

Where, $\mathrm{N} \%=$ Total nitrogen percent; $\mathrm{OM} \%=$ organic matter percent; $\mathrm{C}: \mathrm{N}=$ carbon: nitrogen ratio; $\mathrm{P}=$ phosphorous; $\mathrm{K}=$ potassium; $\mathrm{CEC}=$ cation exchange capacity; $\mathrm{BS} \%=$ base saturation percent

\subsection{Laboratory Analyses}


The soil samples were analyzed at Soil and Plant Analytical Laboratory (SPAL) under NSSC. The plant nutrient parameters analyzed were $\mathrm{pH}, \mathrm{OM} \%, \mathrm{~N} \%, \mathrm{P}, \mathrm{K}, \mathrm{CEC}$, and $\mathrm{BS} \%$ using standard analytical method.

\subsection{Statistical Analysis}

The analytical soil results were analyzed using SPSS 16 for windows. Descriptive statistics of SPSS was used to calculate mean, standard deviation, minimum, and maximum values of quantitative traits. Microsoft Excel spreadsheet was also used to present the soil properties chart.

\section{Result and Discussion}

\subsection{Crop yield}

The average citrus yield in 2013 and 2018 were $3.0 \operatorname{tac}^{-1}$ to $2.6 \operatorname{tac}^{-1}$ respectively. In general there was a decreasing trend in citrus yield over the years.

Citrus trees are not very nutrient demanding, but production of a high quality crop requires adequate amounts of the essential nutrients (Fake, 2004). According to various sources (Table 2), one ton of oranges would remove $1.18-1.85 \mathrm{~kg}$ of N, $0.17-0.27 \mathrm{~kg}$ of P, $1.48-2.61 \mathrm{~kg}$ of K, 0.36$1.04 \mathrm{~kg}$ of $\mathrm{Ca}$ and $0.16-0.19 \mathrm{~kg}$ of $\mathrm{Mg}$. Among nutrients removal, calcium is the most important mineral in vegetative parts while potassium is the dominant mineral in fruits (Erner et al., 1999)

Table 2: Nutrient removal in kg per ton of citrus fruit

\begin{tabular}{lccccc}
\hline \multicolumn{1}{c}{ Author } & $\mathrm{N}$ & $\mathrm{P}$ & $\mathrm{K}$ & $\mathrm{Ca}$ & $\mathrm{Mg}$ \\
\hline Smith and & 1.29 & 0.20 & 1.87 & 0.36 & 0.18 \\
$\begin{array}{l}\text { Reuther (1953) } \\
\text { Chapman (1968) }\end{array}$ & 1.18 & 0.27 & 2.61 & 1.04 & 0.19 \\
$\begin{array}{l}\text { Labanauskas and } \\
\text { Handy (1972) }\end{array}$ & 1.85 & 0.17 & 1.79 & 0.78 & 0.17 \\
$\begin{array}{l}\text { Golomb and } \\
\text { Goldschmidt }\end{array}$ & 1.85 & 0.18 & 1.48 & 1.02 & 0.16 \\
$(1981)$ & & & & & \\
\hline
\end{tabular}

Source: IPI-Bulletin No. 4

\subsection{Farmers' soil fertility and other management practises}

From the survey, it was reported that only $32 \%$ of the farmers apply farmyard manure (FYM).More than $90 \%$ of the farmers tether cattle in the orchards and the tethering duration varied from two to fifteen nights per tree. Only a few farmers (12\%) apply chemical fertilizers. Suphala (NPK 15:15:15) is the only fertilizer used by the farmers. Due to water shortage, about $41 \%$ of the farmers irrigate the plot either once a year $(10.7 \%)$ or twice a year $(30.3 \%)$. The 
irrigation is usually done with a pipe at the basins. The average manure application including both FYM application and tethering was about $10 \mathrm{~kg}$ and $12 \mathrm{~kg}$ per tree for 2013 and 2018 respectively. In general there is a slight increase in manure application rates from 2013 to 2018. The increase in manure application is reported to be due to the requisite to increase citrus yield for income generation.

Among other management practices, fruit drop, leaf miner, and trunk borer are some of the problems reported by the farmers.

\subsection{Soil analysis}

The numbers of soil samples assessed to study the soil fertility status are presented in Table 3 .

Table 3: Number of soil samples evaluated to assess the soil fertility status for citrus orchard

\begin{tabular}{llc}
\hline Soil Variables & 2013 & 2018 \\
\hline & \multicolumn{2}{c}{ No of soil samples } \\
\cline { 2 - 3 } $\mathrm{pH}(\mathrm{H} 20)$ & 270 & 202 \\
$\mathrm{~N} \%$ & 270 & 202 \\
$\mathrm{OM} \%$ & 270 & 202 \\
$\mathrm{C}: \mathrm{N} \mathrm{ratio}$ & 270 & 202 \\
$\mathrm{P}(\mathrm{mg} / \mathrm{kg})$ & 270 & 202 \\
$\mathrm{~K}(\mathrm{mg} / \mathrm{kg})$ & 270 & 202 \\
$\mathrm{CEC}(\mathrm{me} / 100 \mathrm{~g})$ & 270 & 121 \\
$\mathrm{BS} \%$ & 270 & 121 \\
\hline
\end{tabular}

Table 4: Descriptive statistics of soil variables in citrus orchard

\begin{tabular}{llllll}
\hline Year & $\begin{array}{l}\text { Soil } \\
\text { variables }\end{array}$ & Mean & $\begin{array}{l}\text { Std. } \\
\text { Dev }\end{array}$ & Min & Max \\
\hline \multirow{4}{*}{$\mathrm{pH}(\mathrm{H} 20)$} & 5.34 & 0.41 & 4.16 & 6.43 \\
& $\mathrm{~N} \%$ & 0.20 & 0.07 & 0.01 & 0.39 \\
& $\mathrm{C} \%$ & 2.30 & 0.75 & 0.47 & 6.00 \\
& OM\% & 3.62 & 1.60 & 1.90 & 406.04 \\
& $\mathrm{C}: \mathrm{N} \mathrm{ratio}$ & 13.45 & 11.35 & 1.90 & 158.10 \\
& $\mathrm{P}(\mathrm{mg} / \mathrm{kg})$ & 69.36 & 56.94 & 1.64 & 483.31 \\
& $\mathrm{~K}(\mathrm{mg} / \mathrm{kg})$ & 69.36 & 53.80 & 10.23 & 406.04
\end{tabular}


International Journal of Agriculture and Environmental Research

ISSN: 2455-6939

Volume: 07, Issue: 03 "May-June 2021"

\begin{tabular}{lllll}
$\begin{array}{l}\mathrm{CEC} \\
(\mathrm{me} / 100 \mathrm{~g})\end{array}$ & 11.91 & 4.44 & 2.55 & 44.89 \\
$\mathrm{BS} \%$ & 42.14 & 33.90 & 2.77 & 410.86 \\
\hline $\mathrm{pH}(\mathrm{H} 20)$ & 5.07 & 0.55 & 3.82 & 6.70 \\
$\mathrm{~N} \%$ & 0.23 & 0.17 & 0.01 & 1.14 \\
$\mathrm{C} \%$ & 2.37 & 1.08 & 0.01 & 6.30 \\
$\mathrm{OM} \%$ & 4.07 & 1.86 & 0.02 & 10.84 \\
$\mathrm{C}: \mathrm{N} \mathrm{ratio}$ & 13.35 & 9.66 & 0.13 & 80.00 \\
$\mathrm{P}(\mathrm{mg} / \mathrm{kg})$ & 30.04 & 40.13 & 0.03 & 283.60 \\
$\mathrm{~K}(\mathrm{mg} / \mathrm{kg})$ & 60.78 & 60.26 & 0.05 & 405.04 \\
$\mathrm{CEC}$ & 19.98 & 7.69 & 1.36 & 37.09 \\
$(\mathrm{me} / 100 \mathrm{~g})$ & & & & \\
$\mathrm{BS} \%$ & 25.39 & 7.69 & 1.36 & 37.09 \\
\hline
\end{tabular}

\section{$3.4 \mathrm{pH}$ and $\mathrm{OM} \%$}

Although citrus can be planted in soils with either a high or low $\mathrm{pH}$, the optimal soil $\mathrm{pH}$ for citrus ranges from 5.5 to 6.5 (He 1999). In this study, the $\mathrm{pH}$ ranged from 4.16 to 6.43 and 3.82 to 6.70 (table 4) in 2013 and in 2018 respectively. On assessing the soil acidity, it was found that only $34 \%$ (2013) and 24\% (2018) of the samples were within 5.5-6.5 range (table 5). Over 65\% of the samples were within the very acidic to the extremely acidic range (table 5). The mean value of the soil samples were 5.34 and 5.07 (table 4) in 2013 and in 2018 which is lower than the optimum $\mathrm{pH}$ of 5.5. The soils are acidic in nature which could be due to prevailing geology dominated by granitic genesis in the north and phyllite schist in the south (Norbu \& Floyd, 2001) which produce acid, and acidity is aggravated due to leaching and soil erosion which washes alkaline elements (calcium, magnesium, sodium, and potassium) away (Bradford, 2014).

$\mathrm{OM}$ is one of the most important soil fertility indicators and usually its content positively related tocitrus yield (Fang et äl, 2010). Our result showed that the average OM\% content was 3.62 and 4.07 in 2013 (table 4) and in 2018 respectively. Approximately 6-8\% of the samples contain the OM\% within the low range (table 5). Over $90 \%$ of the samples contained OM\% within medium to high level (table5). Similar results were reported by Chhetri et al., 2020 and according to the report, $88.16 \%$ of the orchards in Bhutan recorded OM\% within medium to high range. All the 
citrus growers apply plant nutrients in the form of the FYM and this could be the possible reason for having $\mathrm{OM} \%$ content within the medium range.

Table 5: Classification of no of soil samples into different rating for soil pH and OM\%.

\begin{tabular}{lrrrr}
\hline Rating & \multicolumn{4}{c}{ Year } \\
\cline { 2 - 5 } & \multicolumn{2}{c}{2013} & \multicolumn{2}{c}{2018} \\
\cline { 2 - 5 } Very & pH & OM\% & pH & OM\% \\
\cline { 2 - 5 } low & 58 & 0 & 102 & 0 \\
Low & 121 & 15 & 49 & 17 \\
Medium & 91 & 221 & 49 & 140 \\
High & 0 & 34 & 2 & 45 \\
\hline
\end{tabular}

\subsection{Soil Nutrients}

\subsubsection{N \%, P, and $\mathrm{K}$}

The soil analysis results showed that above $45 \%$ of the soil samples contained N\% within the medium range, whereas $71 \%$ of the soil samples showed $\mathrm{P}$ within medium to high range in 2013. However, the $\mathrm{P}$ level decreased to $56 \%$ (medium to high range) when the soils were tested in 2018 . Above $80 \%$ of the soils are low to very low in K levels. In 2018, the proportions of tested soils that recorded higher than the suggested critical levels were: total nitrogen percent $52 \%$, phosphorus $56 \%$, and potassium $14 \%$ respectively (figure 1 ). It is clear from this long-term study that the quantity of the nutrient applied to citrus is not sufficient and gradually the nutrients are being depleted from the soil. 


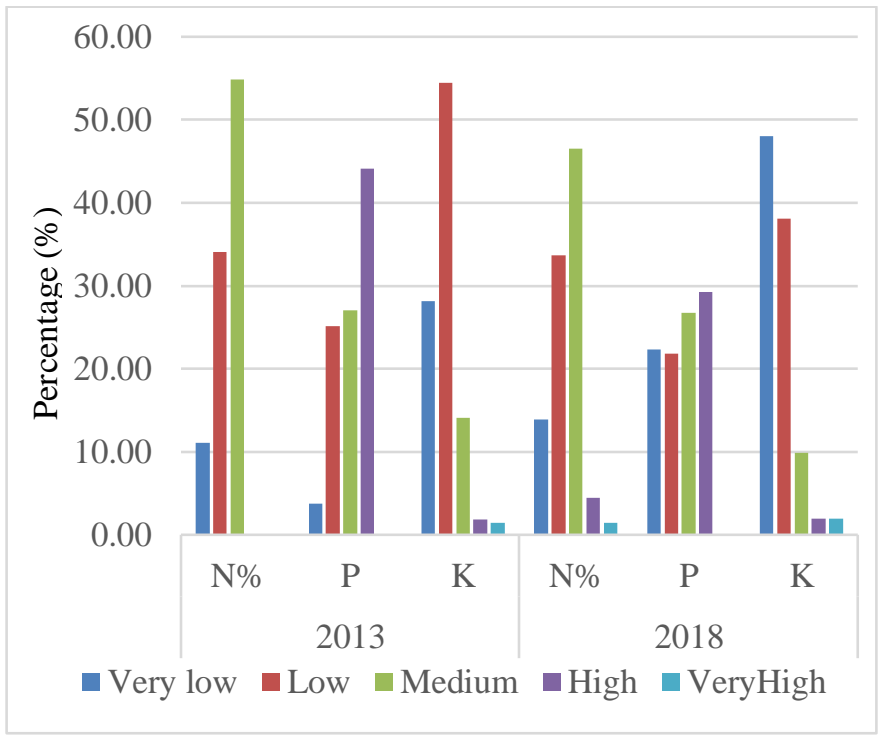

Figure 1: \% N, P, and $\mathrm{K}$ of citrus orchard

\subsubsection{C:N ratio, $\mathrm{CEC}$, and $\mathrm{BS} \%$}

The level of $\mathrm{C}$ : $\mathrm{N}$ ratio varied from 1.9 to 158.10 (Table 4) and 0.13 to 80 with an average of 13.45 and 13.35 in 2013 and in 2018 respectively. More than 80\% (2013) and 70\% (2018) of the soil samples recorded $\mathrm{C}: \mathrm{N}$ ratio levels within to moderate to good range (figure 2 ). The moderate to very good level of $\mathrm{C}: \mathrm{N}$ ratio could be probably due to an adequate level of organic matter content in the soil.

The CEC of the soils ranged from 2.55 to 44.89 and 1.36 to 37.09 (Table 4) in 2013 and in 2018 correspondingly, indicating very low to the very high ability of the soil to hold or store exchangeable cations. The soil analysis recorded $78 \%$ of the soil samples having CEC within low to very low range in 2013, however in 2018, the soil sampled from the same orchard showed improved CEC content with $31 \%$ of the samples within low to medium range (figure 3 ). The mean values (11.91 and 19.98) of the soil samples analyzed were within low range in 2013 and in medium range in 2018 respectively. The probable reason for CEC to improve in 2018 could be due to less application of more nutrients in the form of FYM which improved the soil structure and nutrient holding capacity.

The BS\% of the soils ranged from 2.77 to 410.86 (Table 4) with a mean of 42.14 in 2013. However, in 2018, the soil analysis showed lower BS reading within the range of 1.36 to 37.09 with a mean of 25.39. The level of BS percent of the soils varied from very low to medium (80\%) in 2013 and $95 \%$ in 2018 (figure 3). BS and pH are positively correlated; low pH would 
have low BS (Sanon et al., 2017) that could be the reason having maximum soil samples within very low to medium range.

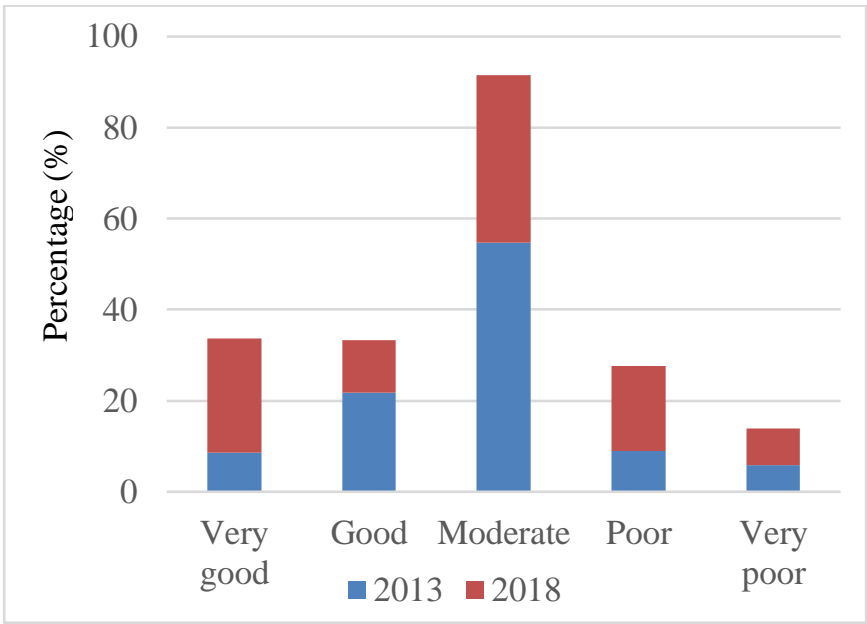

\section{Figure 2: \% CN content of soils of citrus orchard}

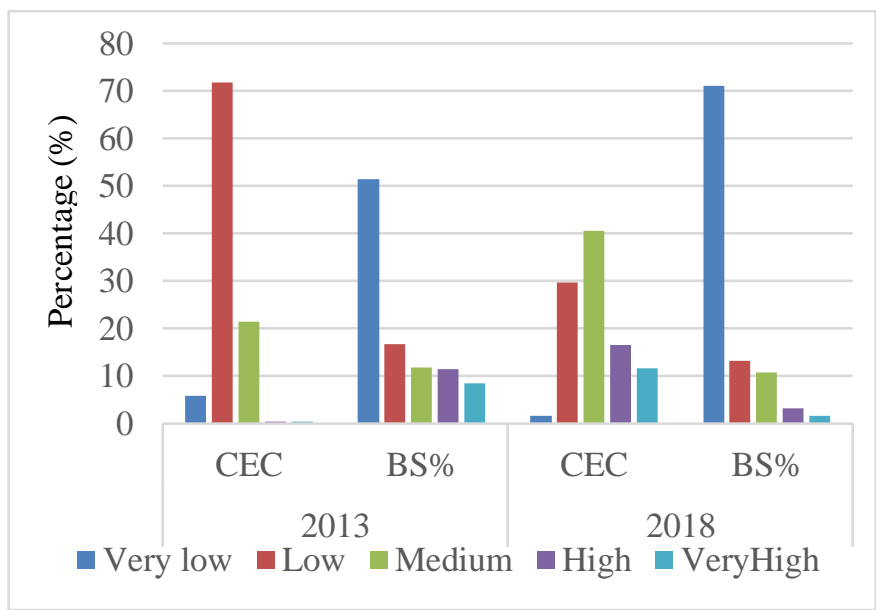

Figure 3: \% CEC, BS content of citrus orchard

\section{CONCLUSION}

Citrus is one of the major sources of income for the farmers in Bhutan. However, citrus yield is very low as compared to other countries. One of the major constraints is low nutrient application. Farmers do apply FYM, the quantity they apply is considerably low, and only handful of farmers use inorganic fertilizers. If the trend continues then there is an enormous risk of depleting soil nutrient stocks thereby deteriorating the soil health. The soil nutrient status rating of the citrus orchard is not encouraging. The mean $\mathrm{pH}$ of the soil is less than 5.5 , within a very acidic range 
and the findings suggest that there is a gradual shift towards thelow $\mathrm{pH}$ values over the years. Without proper $\mathrm{pH}$ amendment, the availability of major nutrients nitrogen, phosphorous, potassium, sulphur, calcium, magnesium, and also the traced element molybdenum is reduced and may be insufficient. The organic matter percent of the soil sample was within the critical limit. However, augmenting soil organic matter could further improve soil structure, nutrient holding capacity and improve crop productivity. The carbon to nitrogen ratio rating was within moderate to very good range, good for citrus production since it allows faster decomposition of soil organic matter and release of excess available nitrogen in the soil. Deficiency of potassium was observed in both years with almost the same numbers of soil samples below the critical level. The finding also indicated that nutrient mining is rapidly occurring as indicated by the decreasing available phosphorous level over the years. The cation exchange capacity has improved, and base saturation percent continued to lower over the years.

\section{RECOMMENDATION}

Lime amendments to correct soil acidity and raising the $\mathrm{pH}$ to optimum level could increase nutrient availability and improve soil structure.

Use more organic manure to improve soil organic matter to improve soil structure, nutrient holding capacity.

There is an urgent need to enhance integrated plant nutrient management technology to improve soil fertility so that an adequate quantity of nutrients is available to citrus and simultaneously maintaining the soil health with acceptable soil nutrient reserve.

\section{REFERENCES}

Joshi, S. R. and Gurung, B. R. Citrus in Bhutan. Value chain analysis (2009)

DoA. Citrus mandarine (2019). Available in http://doa/wp-content/uploads/2019/06/Citrus.pdf

Dorji, K., Lakey, L., Chophel, S., Dechen, S.D.,Tamang, B. Adoption of improved citrus orchard management practices: a micro studyfrom Drujegang growers, Dagana, Bhutan. Agric \& Food Secur (2016)

Drukpa, K. Bhutan RNR statistics (2012)

Bradford, T. Acid soil is made from granite and shale bedrock (2014) 
Norbu, C., \& Floyd, C. Changing soil fertility management in Bhutan: effect on practices, nutrient status and sustainability. Paper presented at the Annual meetings of soil science society of America, Charlotte, NC, USA (2001)

Chhetri, S., Gurung, T. R., Uden, T., Gurung, M., Jamtsho, K. L. Assessment of Soil Fertility Status Using Soil Nutrient Index in Three Land use Systems in Bhutan. Bhutanese Journal of Agriculture 2(1) 60-72(2020)

Sanon, S. L., Saha, K. U., Kissel, E. D. Cation exchange capacity and base saturation(2017) available in https://extension.uga.edu/publication

He, T.F. Mineral Nutrient of Citrus. Citrus. Agriculture Publish House of China, Beijing. 281328 (1999)

Erner, Y., Cohen, A., Mahen, H. Fertilizing for High Yield Citrus, IPI-Bulletin No. 4 (1999)

Fake, C. Fertilizing Citrus inthe Foothills. University of California Cooperative Extension. Publication Number 31-011C(2004) 